\title{
TCOM \\ Barriers to inclusive deliberation and democratic governance of genetic technologies at the science-policy interface
}

\section{Cynthia Taylor and Bryan Dewsbury}

\begin{abstract}
Advances in $21^{\text {st }}$ century genetic technologies offer new directions for addressing public health and environmental challenges, yet raise important social and ethical questions. Though the need for inclusive deliberation is widely recognized, institutionalized risk definitions, regulation standards, and imaginations of publics pose obstacles to democratic participation and engagement. This paper traces how the problematic precedents set by the 1975 Asilomar Conference emerge in contemporary discussions on CRISPR, and draws from a recent controversy surrounding field trial releases of genetically modified mosquitoes to explicate the ways in which these precedents undermine efforts to engage publics in decisions at the science-policy interface.
\end{abstract}

Keywords

DOI

Introduction
Participation and science governance; Public engagement with science and technology

https://doi.org/10.22323/2.18030402

Submitted: 16th July 2018

Accepted: 20th December 2018

Published: 14th June 2019

Rapid advances in genetic technologies are revolutionizing the life sciences and are increasingly being promoted as viable solutions to an array of public health challenges and environmental issues [Bennett and Jennings, 2013; Champer, Buchman and Akbari, 2016; Doudna and Charpentier, 2014; Gao, 2018; Hsu, Lander and Zhang, 2014; NASEM, 2018; Sinkins and Gould, 2006; Tester and Langridge, 2010]. From eradicating infectious diseases and treating genetic disorders, to sustainably improving agricultural productivity and restoring lost biodiversity, the applications of genetic modification and genome editing are seemingly endless. Yet, lurking behind every promise heralded by the 'new genetics' are dystopic imaginations of the future. Myriad uncertainties surrounding the unanticipated impacts of genetic technologies, as well as concerns over the potential for their misuse, "touch on ethical and societal questions that cannot be answered by scientists alone" [Gregorowius, Biller-Andorno and 
Deplazes-Zemp, 2017, p. 355], and necessitate a rethinking of current regulatory standards and modes of public engagement.

The wide-ranging implications of new genetic technologies call for inclusive, public deliberation that incorporates a diversity of stakeholder voices, concerns, and forms of expertise in debates over research and innovation [Benjamin, 2016; Gregorowius, Biller-Andorno and Deplazes-Zemp, 2017; Hurlbut, 2015a; Jasanoff, Hurlbut and Saha, 2015]. In addition to helping to anticipate unforeseen impacts of new technologies, secure public trust and confidence in science, and uphold democratic ideals, such deliberation also works to expand society's collective "ethical imagination" [Benjamin, 2016, p. 54]. However, opportunities for inclusive deliberation and democratic governance of emerging technologies are bounded by culturally-specific, institutionalized imaginations of the risks and benefits of innovation, the proper roles of experts and non-experts in state-science-society relations, and the meaning of 'public good' [Burri, 2015]. The ways in which publics are constructed, through institutional, regulatory, and expert discourses, influence communication, engagement, and stakeholder involvement in policy decisions [Barnett et al., 2012]. Moreover, regulatory norms for identifying, assessing, and managing potential risks establish the parameters of permissible discourse, and shape the extent to which diverse voices are heard in matters of policy and technology implementation.

This paper explores institutionalized standards of governance and engagement surrounding genetic technologies in the United States, and how they relate to practices of inclusion and exclusion in public deliberations. This exploration begins with a discussion of the Asilomar Conference on recombinant DNA in 1975, and the problematic precedents it set in terms of governance and engagement. We then turn our attention to how the legacy of Asilomar informs current discussions on CRISPR-Cas9 genome editing, ${ }^{1}$ and the ways in which Asilomar-based standards for regulation and engagement are simultaneously challenged and upheld. Finally, lessons for responsible governance and inclusive deliberation are gleaned from a case study of a recent controversy surrounding proposed field trial releases of genetically modified mosquitoes in the Florida Keys to control vector-borne disease. We use this case to further elucidate current challenges to public engagement, inclusive deliberation, and democratic governance.

Asilomar, risk governance, and imagined publics
In the early 1970s, the development of recombinant DNA (rDNA), the backbone of pre-CRISPR biotechnology, was met with swift concerns from both inside and outside laboratories in the U.S. In light of the uncertainties and potential dangers of this new technology, scientists called for, and agreed upon, a voluntary moratorium on rDNA research in 1974. The following year, a group of preeminent molecular biologists, lawyers, and other specialists, convened at the Asilomar Conference

\footnotetext{
${ }^{1}$ Unlike traditional recombinant DNA technologies that rely on restriction endonucleases (bacterial proteins) to cut and reassemble genetic material from different organisms, the CRISPR (Clustered Regularly Interspaced Palindromic Repeat segments of prokaryotic DNA) technique utilizes RNA sequences to target specific regions of a host's genome through complementary base-paring. When combined with Cas9 (a CRISPR derived enzyme), these RNA sequences can be used to add, remove, or alter genomes, once inserted into host cells. When compared to recombinant DNA technology, CRISPR-based techniques for gene editing have been heralded as a cheaper, simpler, and more precise method of genome editing. Moreover, CRISPR allows for multi-gene editing, rather than just single gene modifications.
} 
Center in Pacific Grove, California to assess the risks of rDNA and establish guidelines for how to proceed safely and responsibly with research. After three and a half days of discussion, the conference culminated in a set of agreed upon risk containment guidelines that allowed for the moratorium to be lifted.

The Asilomar Conference has been hailed as a great success story of scientific solidarity, that curbed public anxieties and charted the course towards a "commercially successful biotechnological future"[Hurlbut, 2015a, p. 12]. Beneath the surface, however, Asilomar is also a story of scientists redrawing the boundaries between science, policy, and society in ways that helped position science as the most qualified institution to define and regulate biotechnology's risks [Gottweis, 1998]. Throughout the meetings, conference discussions worked to narrow risk definitions to technical matters only. By failing to engage with the social, economic, and ethical issues surrounding rDNA research and applications, the conference set a precedent for treating such issues as "outside the scope of regulation" [Parthasarathy, 2015, p. 308].

In official statements summarizing the meetings, organizers concluded that, while the risks of recombinant DNA couldn't be denied, they could be contained through both physical and biological barriers [Berg et al., 1975]. As such, risks could be controlled by the very technologies that created them in the first place [Gottweis, 1998]. The conference further established that the magnitude of risk surrounding biotechnologies could be adequately estimated by expert discernments of novelty [Hurlbut, 2015b]. This same logic informs the regulation of genetically modified organisms in the U.S., as evidenced by the centrality of substantial equivalence-based risk assessments that determine the safety of genetically modified products by comparing them to their non-genetically modified counterparts [Burchell, 2007].

In post-Asilomar deliberations on new genetic technologies, retellings of the conference's success in establishing public trust function to reproduce institutionalized imaginations of publics and the 'proper' role of citizens in science and technology governance. J. Benjamin Hurlbut [2015b] observes:

\footnotetext{
"... the public role that the Asilomar story celebrates is one of dependence, with the public passively learning — and deferring to - science's authoritative judgment about what is at stake and when a democratic reaction is warranted. The legacy of Asilomar lies less in its scientific achievements than in its implications for democratic governance of science and technology" (p. 12).
}

Asilomar's establishment of an 'expert enclosure' [Gottweis, 1998, p. 104] around risk governance, risk definitions, and risk evaluations was facilitated by the fact that non-expert voices were deliberately excluded from participating in conference discussions. Expert imaginations of a public that was reactive and unqualified to weigh in on debates, combined with a narrowing of risk discourses to strictly technical matters, legitimized and justified this exclusion for conference organizers. Paradoxically, in failing to provide opportunities for proactive public engagement, Asilomar reified these imaginations of a reactive public in that, for citizens, reactive roles were the only ones available to them [Hurlbut, 2015a]. 
Asilomar's legacy in times of CRISPR
Unsurprisingly, the recent CRISPR revolution has inspired a revisiting of Asilomar's legacy in the scholarly literature [Greely, 2015; Gregorowius, Biller-Andorno and Deplazes-Zemp, 2017; Hurlbut, 2015b; Hurlbut, 2015a; Jasanoff, Hurlbut and Saha, 2015; Parthasarathy, 2015]. The precision, affordability, and accessibility of CRISPR-based applications, are making possible not just alterations to the genomes of single organisms, but the genetic transformation of entire species [Braverman, 2017]. CRISPR's potential to eradicate disease, restore lost biodiversity, and sustainably improve agricultural productivity, are paralleled by concerns over new eugenics movements, off-target mutations in genomes, and irreversible harm to the environment. The unprecedented pace and scale at which CRISPR can transform life forms, and ecosystems, combined with possibilities for its misuse, require careful reevaluations of current regulatory standards, as well as "the relationship between science and democracy" [Jasanoff, Hurlbut and Saha, 2015, para. 7].

The need for new modes of inclusive deliberation on CRISPR and its applications is widely recognized by scientists, ethicists, policy-makers and activists. In addition to identifying potential biological and ecological impacts, careful consideration must be paid to the ways in which the applications of CRISPR intersect with issues of social justice and equality. As Ruha Benjamin [2016] reminds us, "innovation and inequity too often go hand-in-hand" (p. 52). She writes:

\begin{abstract}
"Gene editing techniques are seeded with values and interests - economic as well as social - and without careful examination, they will easily reproduce existing hierarchies, including assumptions about which lives are worth living and which are worth 'editing' out of existence" [Benjamin, 2016, p. 52]
\end{abstract}

Additionally, CRISPR-based applications such as gene drives ${ }^{2}$ problematize issues of jurisdictional control, accountability, and governance. Designed to bypass the rules of Mendelian inheritance, gene drives can rapidly alter the genetic makeup of species and can be used to alter animal vectors (so that they are no longer able to transmit disease), suppress or eliminate invasive organisms, and enhance the resilience of endangered populations to ecological changes. But, as Kevin Esvelt (one of the developers of genes drives) warns, "a release [of gene drives] anywhere, is likely a release everywhere" (cited in Le Page [2016] para.1). The ease at which gene drives can transgress both local and national boundaries makes it impossible to obtain consent from all of the stakeholders that might be affected by (and opposed to) this technology, raising questions related to power, sovereignty, and political relations at both local and global scales.

Despite seemingly widespread agreement amongst social scientists and molecular biologists that the Asilomar Conference is a poor model on which to base CRISPR governance and deliberation, concerns over CRISPR have also culminated in Asilomar-style reenactments of scientific solidarity and self-regulation that are bringing both new and old issues into sharper relief. For example, in 2015, CRISPR developer Jennifer Doudna and other leading experts called for a global moratorium on human gene-editing. Later that year, 500 people, including

\footnotetext{
${ }^{2}$ Gene-drives are technologies that harness the editing capabilities of CRISPR to introduce desired genes into populations. Because these introduced genes contain CRISPR components, they increase the odds of inheritance during reproduction and can be quickly propagated, leading to the widespread genetic transformation of an entire population over a short period of time.
} 
biologists physicians, bioethicists, social scientists, journalists, and public advocacy groups, gathered at an international summit organized by the National Academy of Sciences in Washington, D.C. Though modeled on the Asilomar conference, the summit diverged both in terms of the heterogeneity of participants and scope of discussions (many of which extended to ethics and the need for inclusive deliberation). Of particular emphasis was the need for diverse stakeholder participation, that included the individuals and groups who were likely to be the most directly impacted by CRISPR technologies and/or the most frequently excluded from policy decisions [Baker, 2016].

Though it was undoubtedly guided by important ethical considerations, the move towards a global moratorium was also an expression of scientific authority and its capabilities to decide what, when, and how technoscientific futures should be pursued. This was exemplified by the fact that scientists made a unilateral decision to halt gene-editing in the interest of democratic governance and public good. However, those stakeholders that were most likely to be directly impacted by CRISPR technologies and left out of discussions (such as individuals with life threatening genetic diseases), were also those who were most likely to be affected by a moratorium on research that might prove to be life-saving. Even so, these voices were included in discussions only after the moratorium had been decided, again, casting them into necessarily reactive roles.

In response to the pressing need for responsible governance of CRISPR-based research and applications, the National Academies of Science, Engineering and Medicine (NASEM) drafted a series recommendations to guide responsible gene-drive practices [NASEM, 2016]. These recommendations, outlined in NASEM's 218 page report, touch on multiple issues related to biosafety, governance, accountability, education and engagement. Sponsors and supporters of gene drive research further developed these recommendations and aligned them with a set of guiding principles [Emerson et al., 2017] which are summarized in Table 1.

With regard to CRISPR-based applications in non-human organisms, gene-drive developer Kevin Esvelt has advocated for a more radical approach, aimed specifically at dealing with CRISPR's potential for misuse as well as enhancing public trust and securing adequate measures of biosafety. His proposed framework for governance intends to mobilize a well-organized assemblage of stakeholders and legal instruments [Hilgartner, 2017] to "[re]engineer the scientific ecosystem" [Esvelt, 2017, p. 29]. On this 'scientific ecosystem,' Esvelt [2017] writes:

\footnotetext{
"It is the catalyst with which we can demand change from those who control the incentives: scientific journals, funders, policy makers, and holders of intellectual properties." (p. 29).
}

Esvelt's plan is to convince funders and science journals to set strict guidelines mandating full transparency and public disclosure of proposed gene drive research before agreeing to fund and publish this research. Additionally, Esvelt intends to collaborate with policy makers to leverage gene drive patents (to which he holds the property rights), to force future researchers into compliance. Accordingly, under this plan, permission to Esvelt's licenses will be granted only to those 
Table 1. Guiding principles for responsible CRISPR/gene drive research and governance.

Advance quality science to promote the public good.
The pursuit of gene drive research must be motivated by, and aim to promote, the public
good and social value. Funded research shall embody the highest quality science and ethical
integrity, consistent with the current best practice guidance set by the research community
and relevant decision-making bodies. (In alignment with NASEM recommendations 5-1, p. 106).

Promote stewardship, safety, and good governance.

Researchers and sponsors are stewards of science and the public trust. It is imperative that good governance is demonstrably shown in all phases of the research, and especially in relation to risk assessment and management. This requires compliance with applicable national and international biosafety and regulatory policies and standards. Research conducted with respect and humility for the broader ecosystem in which humans live, taking into account the potential immediate and longer-term effects through appropriate ecological risk assessment, is a hallmark of both good stewardship and good governance. (In alignment with NASEM recommendations 6-1, p. 128; 8-3, 8-4, and 8-10, pp. 170-172).

Demonstrate transparency and accountability.

Knowledge sharing is not only essential for the advancement of science, but for transparency to foster public trust in emergent technologies. The timely reporting of results and broad sharing of data shall be the norm in gene drive research, consistent with the tradition of openness established in its parent communities of genetic and genomic science. Measures of transparency and accountability that contribute to building public trust and a cohesive community of practice will be supported [(2), pp. 171, 177-178)]. (In alignment with NASEM recommendations 8-5 and 8-7 p. 171, 9-2 p. 177, and 9-5 p. 178).

Engage thoughtfully with affected communities, stakeholders, and publics.

Meaningful engagement with communities, stakeholders, and publics is critical for ensuring the best quality science and building and sustaining public confidence in the research. Funded research shall include the resources needed to permit robust, inclusive, and culturally appropriate engagement to ensure that the perspectives of those most affected are taken into account. (In alignment with NASEM recommendations 7-1 through 7-8, pp. 142-143).

Foster opportunities to strengthen capacity and education.

Strengthening capacities in science, ethics, biosafety, and regulation is essential for enabling agile and steady progress in gene drive research globally. Opportunities to partner, educate, and train shall be supported throughout all phases of the research, from the early stages to deployment. Strengthening capabilities within countries for testing and deploying the technology is essential for informed decision-making. (In alignment with NASEM recommendations 6-1, p. 128; 8-1, 8-2, 8-5, 8-7, 8-8, and 8-10, pp. 170-172).

Adapted from Emerson et al. [2017].

researchers who demonstrate full compliance with standards of transparency and public openness surrounding their plans for use [Esvelt, 2017]. On closer inspection, one sees shadows of Asilomar in this regime. Guided by the idea that science must maintain the power of governing itself (since it is the only institution qualified to do so), Esvelt's framework continues to expand the boundaries of science deeper into the territories of law and public policy.

In thinking about challenges to inclusive deliberation in matters related to the future of CRISPR, it is instructive to explore recent controversies involving non-CRISPR based genetic technologies to explicate the ways in which stakeholder 
involvement in decision-making unfolds. In what follows, a controversy surrounding the use of genetically modified (GM) mosquitoes in the Florida Keys is presented as a lens through which we magnify some barriers to democratic participation that are relevant to discussions of CRISPR. Of particular interest are the ways in which scientific standards of self-regulation, narrow risk definitions, and imaginations of publics, embed modes of governance in ways that undermine public trust and opportunities for inclusive deliberation of new technologies.

GM mosquitoes: governance, regulation and public engagement
In 2010, the Florida Keys Mosquito Control District (FKMCD) began collaborating with the British biotechnology company Oxitec to lay the groundwork for field trial releases of Oxitec's genetically modified mosquito (OX513A Aedes aegypti) in the Florida Keys. Developed in the pre-CRISPR era of biotechnology, Oxitec's approach relies on traditional recombinant DNA technology to suppress mosquito populations and control the spread of mosquito borne diseases. Though Oxitec had implemented its technologies in other countries, the proposed field trial was slated to be the first time a genetically modified animal was released into an open environment in the United States. Release plans were submitted by Oxitec to the US Food and Drug Administration (FDA) in 2011 for regulatory approval. News of the release plans were met with intense opposition from local and national environmental groups, and concerned residents mobilized resistance in town hall meetings and through social media campaigns. Public criticisms of the plans were centered on questions regarding possible unintended consequences of OX513A releases on local ecosystems, Oxitec's for-profit motives, institutional rigor in risk assessment, and the degree to which different stakeholders could influence policy decisions.

Nevertheless, after 5-years of tense scientist-resident relations, the FDA released its preliminary findings in 2016, stating that the proposed Oxitec field trials posed no significant risk to human health or the environment, and solicited public input on its assessment [U.S. Food and Drug Administration, 2016]. Upon reviewing 2,641 online public comments (mostly in opposition), the FDA released its final assessment that August supporting the release plans. Amidst growing public dissidence, elected officials decided to put the field trial plans to a non-binding vote in the November 2016 elections. Though the releases were backed by $58 \%$ of voters in the Florida Keys, $65 \%$ of voters who resided in the proposed release area voted in opposition [Atkins, 2016]. In light of these divided polls, officials from the Florida Keys Mosquito Control District made the decision not to move forward with the field trials. Updates to biotechnology regulatory frameworks in the U.S. in 2017 transferred oversight of Oxitec's mosquitoes to the Environmental Protection Agency [U.S. Food and Drug Administration, 2017]. On November 28, 2018, Oxitec, Ltd. issued a press release stating that the company would be phasing out the use of OX513A mosquitoes and replacing them with their newly developed, $2^{\text {nd }}$ generation OX5034 mosquitoes ${ }^{3}$ [Oxitec Ltd., 2018]. That same day, a Florida Keys Mosquito Control District press release was circulated on the Florida Keys Environmental Coalition group's Facebook page announcing that Oxitec was withdrawing its permit for experimental use of OX513A and resubmitting a new

\footnotetext{
${ }^{3}$ Unlike OX513A, the use of OX5034 technology permits multigenerational suppression, in that matings between OX5034 males and wild type females result in the survival of male progeny only, who continue to propagate self-limiting genes within the population. According to Oxitec, this will result in greater scalability and cost-effectiveness of releases.
} 
application to the EPA for an OX5034 field trial permit in the coming months [The Florida Keys Environmental Coalition, 2018].

From the start, the on-going controversy in the Florida Keys was largely fueled by the governance/risk philosophies and imagined publics that Asilomar helped to institutionally inscribe. These philosophies and imaginations undermined efforts to involve residents in discussions in meaningful ways, and manifested across multiple sites of stakeholder engagement. Matters were further complicated by the underlying market frameworks that shape the production, regulation, and communication of new biotechnologies, like genetically modified organisms [Meghani and Kuzma, 2018]. These issues are explored below, using stakeholder statements from two Florida Keys town hall meetings (2012 and 2014). Over four hours of audio video recordings were obtained the through the FKMCD website and YouTube and transcribed by the authors with the help of an undergraduate research assistant in the Science, Education and Society Program at the University of Rhode Island.

Participants present during the meetings were identified as members of at least one of following stakeholder groups, ${ }^{4}$ with varying levels of authority and expertise: 1 ) Oxitec Ltd., 2) the Florida Keys Mosquito Control District, 3) Unaffiliated Scientists, 4) Local Policy Makers/ Advisors/Public Figures, 5) Federal Regulators, 6) Residents, and 7) Activists. Oxitec, the FKMCD, and residents emerged as the most vocal and organized stakeholder groups during the meetings. It is important to note that most comments in support of the Oxitec field trials were contributed by scientists (both affiliated and unaffiliated with Oxitec and/or the FKMCD) and other public officials. The combined number of resident commenters for both meetings totaled 45 (14 for the 2012 meeting, and 31 for the 2014 meeting). Only one resident, a scientist, offered explicit support for the field trial plans. The majority of resident statements were either neutral or in explicit opposition to the field trial plans. We caution, however, that the views presented in the meetings may not necessarily be representative of Florida Keys residents at large, as some residents appeared to also be members of environmental activist groups.

\section{2 and 2014 town hall meetings}

As previously mentioned, at the time the town hall meetings were held, regulatory decisions surrounding the use of Oxitec's mosquitoes in the Keys were playing out under the FDA's guidance and oversight. Meghani and Kuzma [2018] conducted an in-depth analysis of the FDA's regulatory procedures as they pertained to Oxitec's GM mosquitoes, and are critical of the fact that the FDA made the decision not to assess field trial plans at the most stringent level of a 3-category environmental review system. This would have mandated increased requirements of detail and rigor in assessment. Instead, the FDA allowed Oxitec to submit an Environmental Assessment in which "Oxitec chose to use a qualitative risk assessment method that combines phrases of 'likelihood' with phrases of 'consequence' to estimate risk qualitatively' based on summaries of research the company itself had conducted" [Meghani and Kuzma, 2018, p. 214]. Residents in attendance at the 2014 town hall meetings were equally critical of the FDA's risk assessment:

\footnotetext{
${ }^{4}$ These groups are not mutually exclusive, in that some participants belonged to more than one group of stakeholders. For example, several scientists in attendance (unaffiliated with Oxitec and the FKMCD) were also residents. Likewise, cross-checking research online revealed that several residents in attendance were also members of activist groups.
} 


\begin{abstract}
"Any drug that has been taken off the market by the FDA was at one time approved by the FDA. I think the concern that people have, or that, well, certainly that I have, is to understand any kind of independent evaluation that the FDA might be making, to be reassured that somehow whatever might come, is planned for, that we don't find ourselves in a few years in a situation with consequences that could not be anticipated." - Public comment [Catherine, 2014]
\end{abstract}

The degree to which institutional confidence was placed in Oxitec's ability to define, assess, self-regulate, and accurately report on the risks of its product speaks to the centrality of scientific authority in policy matters, and was a common concern raised by residents throughout the controversy. The FDA's deference to scientific authority was matched by its commitment to neoliberal agendas articulated in the long-standing 1986 Coordinated Framework on the Regulation of Biotechnology [Meghani and Kuzma, 2018]. This framework institutionalized the market-based logic of substantial equivalence in biotechnology regulation, stating that it would allow the U.S. to be a global leader in biotech development and commercialization by facilitating the pipeline from industry to market. This put public health interests in direct tension with those of industry and market. Yet, White House revisions to the framework in 2015 and 2017 further reinforced its commitment to neoliberalism, citing that the goal of these revisions was to 'ensure public confidence' and 'prevent unnecessary barriers to innovation' (White House [2015] cited in Meghani and Kuzma [2018, p. 5]).

Under the neoliberalist ideology of U.S. regulation, the market itself becomes the primary mode of governing risk and innovation and the public is constructed as consumers [Burri, 2015; Jasanoff, 2005]. As we have seen with Asilomar, how publics are imagined largely shapes how engagement strategies and communication unfolds. When publics are imagined by scientists and regulators to be uninformed consumers (and reactive ones at that), communication between stakeholders tends to be asymmetrical (mainly consisting of experts attempting to inform citizens so that they may be more likely to buy in to technologies). The deep and murky relationship between biotechnology governance, market frameworks, and communication was not lost on opponents to the Oxitec field trials, making it difficult for some residents to discern where risk communication ended and public relations began. In their attempts to assess and, at times, undermine the companies risk claims, many residents and national advocacy groups took it upon themselves to conduct scientific 'audits' [Curry, 2010] on the company and their financial dealings. During a 2012 town hall meeting one resident commented:

\footnotetext{
"I would like to know what peer reviews you have that are not funded by your company. Also, are you funded by the Bill and Melinda Gates foundation? I read somewhere that your company is losing 2.7 million a year since it's been founded. You obviously have many investors. One of them being a Boston banker that you're set to pay back a debt to at the beginning of 2013. I just wanna know, is that true?" - Public comment [Florida Keys Mosquito Control District, 2012]
}

Others were equally skeptical about how claims to intellectual property rights and proprietary patents were affecting scientist's ability to self-regulate through peer review: 
"I haven't seen enough third party objective research to really substantiate the claims of success that you've had in other countries. This [genetically modified mosquito] is a proprietary patented product. Who else has had access to research your product without doing wild experimentation? I understand that there's been research by collaborators, but collaborator, by definition, is not an objective term. I'm really talking about independent third party, objective research." - Public comment [Florida Keys Mosquito Control District, 2012]

These comments align well with Wynne's [2001] observations that in many cases of controversy "public reactions are not reactions to (supposedly misperceived) risks as such, or to media representations of these, but rather are public judgements of dominant scientific and policy institutions, and their behaviors - including their representations of the public" (p. 445).

This is not to say that perceptions of risk do not matter nor that public misperceptions do not play a role in scientific controversies. Indeed, at several points in the town hall meetings (and throughout the controversy in general) public misperceptions of science and scientific topics presented obstacles for productive deliberation and engagement. More relevant to this paper, however, are the ways in which scientists' commitment to treating risk as strictly a technical matter undermined democratic deliberation. Though the decision to release Oxitec's mosquitoes was eventually brought to referendum, in early discussions the Florida Keys Mosquito Control District advocated for technocratic governance. As the director of the FKMCD explained:

\begin{abstract}
"The people that make these decisions, I want to be the people who have the scientific background to evaluate risk. And that's really what this is all about. Is the risk of any future mosquito borne disease worse than the risk of a new technology?" - FKMCD Director comment [Florida Keys Mosquito Control District, 2012]
\end{abstract}

Yet, the releases of genetically modified mosquitoes were about much more than the measuring of disease risk against the risk of technology for residents at the meetings. They were about the dangers of transforming society into a laboratory, residents' place-based identities and emotional connections to the Florida Keys environment and its inhabitants (both human and non-human), matters of power and responsibility in who gets to decide the future, and issues of autonomy and consent when it comes to experimenting with genetically modified organisms in people's backyards [Herndl and Zarlengo, 2018].

The parameters of discourse, set by exclusively technical definitions of risk, prevented Oxitec scientists and the Florida Keys Mosquito Control district from engaging meaningfully with these complex issues, resulting in residents feeling that their voices were not being heard [Herndl and Zarlengo, 2018; Phillips, 2017]. Further complicating the situation, were scientists narrow definition of engagement. In scientific publications and promotional materials, Oxitec frequently calls attention to the many ways in which the company conducts outreach and engagement in areas where releases of GM mosquitoes are carried out. However, during the 2012 town hall meeting, one resident, with Oxitec promotional materials in hand, pointed out: 


\begin{abstract}
"You say that you have a community engagement plan in place. This is a question of integrity, so please bear with me. You say that you that have conducted, so far, have consisted of public information events. Where have those taken place? And has anyone in this room been to one?"-Public comment [Florida Keys Mosquito Control District, 2012]
\end{abstract}

Her question was addressed by an FKMCD staff member:

\begin{abstract}
"I do all the public outreach through mosquito control, and I've talked to the county commission, the Key West City Commission, there's been articles in the newspaper. We're on the radio every week." - FKMCD staff member comment [Florida Keys Mosquito Control District, 2012]
\end{abstract}

The resident followed up on these remarks, stating:
"So for integrity's purposes Oxitec states, that to date, 'community engagement activities, so far, consisted of public information events'. I just wish to say gentlemen, I want to trust in your highest intent as scientific people, not dollar driven. But please understand that when statements like this are in your own document, it gives us pause."

This exchange reveals that an understanding of 'community engagement' may mean different things to different stakeholders. It seems that both Oxitec and the FKMCD were defining engagement, at least at that time, primarily in terms of media outreach. ${ }^{5}$ Resident statements articulate a dissatisfaction with this shallow level of engagement in such important matters and demonstrate how easily trust can be eroded when the language of engagement does not accurately represent actual engagement practices. Moreover, in the case of the Florida Keys controversy, the public was only invited to participate in field trial discussions after release plans had already been set in motion, leading many residents to feel that the town hall deliberations were nothing more than a 'dog and pony show' [Catherine, 2014; Florida Keys Mosquito Control District, 2012].

\title{
Conclusion: lessons for CRISPR
}

The controversy surrounding the use of GM mosquitoes in the Florida Keys offers several important lessons that are relevant to discussions on CRISPR in its early stages of application and implementation. First, the goals of inclusive deliberations on new genetic technologies are unlikely to be achieved if scientists are unwilling to yield control over exclusive definitions of risks. Limiting risks to technical matters reduces the scope of discourse in a way that is detrimental not only to science-society relations, but also to responsible modes of governance that consider not just the biological/ecological harm of new technologies but the social consequences as well. While CRISPR deliberations seem much more attuned to ethical considerations, it is important to remember that the current regulatory frameworks for biotechnology governance in the U.S. (under which CRISPR and its products are likely to be regulated), are centered on a definition of risk as exclusively technical in nature. If ethical deliberations are to be reflected in ethical regulations, we must rethink how risk is defined at the regulatory level as well.

\footnotetext{
${ }^{5}$ In subsequent years, Oxitec began campaigning door to door and through telephone calls.
} 
Second, the standard for scientific self-regulation combined with the neoliberalized modes of market governance written into regulatory frameworks, may undermine the ability of regulatory agencies to prioritize safety in regulatory decisions and can contribute to the erosion of public trust. Discussions of CRISPR governance must be scrupulously attentive to these matters, as well as the ways in which modes of governance reproduce particular imaginations and representations of the public, as this affects how deliberation and engagement is carried out. Persistent, institutionalized imaginations of publics as reactive consumers present major obstacles for transparent, inclusive, and symmetrical communications between scientists and the communities they engage with. In striving for more democratic forms of deliberation, publics must be reimagined as active participants who are capable of making contributions to discussions on new technologies and their implications.

Finally, stakeholders in science-related policies may hold different understandings about what engagement means. When expectations for engagement are not met, or engagement practices are inconsistent with the language used to describe it, publics may feel that they are being left out of the decision making process and/or deceived. In thinking about CRISPR, clearer definitions and standards of engagement are needed. Inclusive deliberation on CRISPR technologies should also include discussions on what engagement means and for whom, as well as what forms of engagement are needed to ensure that diverse voices are included, heard, and served by these deliberations. Moving forward, it is imperative that the terms of CRISPR engagement are set democratically, and in ways that work to empower citizens and their communities in the governance of new technologies.

The NASEM [2016] recommendations for governing gene drives are a step in the right direction in thinking about responsible CRISPR practices, including modes of public engagement (see sections 7-1 to 7-8 of the NASEM report). Target Malaria (a non-profit group researching the use of gene drives for vector control) for example, has aligned their governance and engagement strategies closely with the NASEM recommendations in efforts to engage diverse stakeholder voices, cultivate public confidence, and incorporate local values into governance practices in areas where gene-drive mosquitoes are being considered for release [Target Malaria, 2016]. Had similar recommendations been developed, articulated, and adhered to during early discussions of Oxitec's field trials, it is possible that some of the controversy in the Florida Keys may have been prevented (or at least tempered). Still, there are problematic gaps in NASEM's recommendations that need to be carefully considered moving forward. For example, Neuhaus [2018] points out that the vagueness of the definition of 'community engagement' that so haunted the Oxitec trials in the Florida Keys, is not adequately resolved in NASEM's report. Moreover, NASEM's report "fails to acknowledge the strong commercial drivers that may bring gene drives into use" [Thomas, 2016, n.p.]. Future research on CRISPR and its applications need to be especially attentive to these gaps and work to narrow them, lest they undermine frameworks for precautionary governance and inclusive deliberation.

References

Atkins, K. (8th November 2016). 'In Florida Keys, most voters favor GMO mosquito release experiment'. Miami Herald. URL: https : //www . miamiherald.c om/news/politics-government/election/article113478728.html (visited on 14th July 2018). 
Baker, B. (2016). 'The ethics of changing the human genome'. BioScience 66 (4), pp. 267-273. https://doi.org/10.1093/biosci/biw017.

Barnett, J., Burningham, K., Walker, G. and Cass, N. (2012). 'Imagined publics and engagement around renewable energy technologies in the U.K.' Public Understanding of Science 21 (1), pp. 36-50. https://doi.org/10.1177/0963662510365663.

Benjamin, R. (2016). 'Interrogating equity: a disability justice approach to genetic engineering'. National Academies of Science. Issues in Science and Technology 32 (3). URL: https://issues .org/interrogating-equity-a-disability-justice-ap proach-to-genetic-engineering/.

Bennett, D. J. and Jennings, R. C. (2013). Successful agricultural innovation in emerging economies: new genetic technologies for global food production. Cambridge, U.K.: Cambridge University Press. https://doi.org/10.1017/CB09781139208475.

Berg, P., Baltimore, D., Brenner, S., Roblin, R. O. and Singer, M. F. (1975). 'Summary statement of the Asilomar conference on recombinant DNA molecules'. Proceedings of the National Academy of Sciences 72 (6), pp. 1981-1984. https://doi.org/10.1073/pnas.72.6.1981.

Braverman, I. (2017). 'Editing the environment: emerging issues in genetics and the law'. In: Gene editing, law and the environment. Ed. by I. Braverman. New York, NY, U.S.A.: Routledge. URL: https: //papers. ssrn. com/abstract=3032590.

Burchell, K. (2007). 'Boundary work, associative argumentation and switching in the advocacy of agricultural biotechnology'. Science as Culture 16 (1), pp. 49-70. https://doi.org/10.1080/09505430601180896.

Burri, R. V. (2015). 'Imaginaries of science and society: framing nanotechnology governance in Germany and the United States - university press scholarship'. In: Dreamscapes of modernity: sociotechnical imaginaries and the fabrication of power. Chicago, IL, U.S.A.: University of Chicago Press, pp. 233-253. https://doi.org/10.7208/chicago/9780226276663.003.0011.

Catherine, C. (2014). FKMCD Town Hall Meeting - 120414. [YouTube video]. URL: https://www youtube . com/watch?v=f031wLQoCJO.

Champer, J., Buchman, A. and Akbari, O. S. (2016). 'Cheating evolution: engineering gene drives to manipulate the fate of wild populations'. Nature Reviews Genetics 17 (3), pp. 146-159. https://doi.org/10.1038/nrg. 2015.34.

Curry, J. (2010). On the credibility of climate research, part II: towards rebuilding trust. URL: http://curry.eas.gatech.edu/climate/towards_rebuilding_trust.ht $\mathrm{ml}$ (visited on 15th September 2018).

Doudna, J. A. and Charpentier, E. (2014). 'The new frontier of genome engineering with CRISPR-Cas9'. Science 346 (6213), pp. 1258096-1258096. https://doi.org/10.1126/science.1258096.

Emerson, C., James, S., Littler, K. and Randazzo, F. (2017). 'Principles for gene drive research'. Science 358 (6367), pp. 1135-1136. https://doi.org/10.1126/science. aap9026.

Esvelt, K. M. (2017). 'Rules for sculpting ecosystems: gene drives and responsive science'. In: Gene editing, law and the environment: life beyond the human. Ed. by I. Braverman. 1st ed. New York, NY, U.S.A.: Routledge, pp. 20-37. https://doi.org/10.4324/9781315168418-2.

Florida Keys Mosquito Control District (2012). Town hall meeting. [YouTube video]. URL: https : / /wWw . youtube. com/watch?v=5WQkM-yc7QI. 
Gao, C. (2018). 'The future of CRISPR technologies in agriculture'. Nature Reviews Molecular Cell Biology 19 (5), pp. 275-276. https://doi.org/10.1038/nrm.2018.2.

Gottweis, H. (1998). Governing molecules: the discursive politics of genetic engineering in Europe and the United States. Cambridge, MA, U.S.A.: The MIT Press.

Greely, H. (4th April 2015). Of science, CRISPR-Cas9 and Asilomar. URL: https: // law .stanford.edu/2015/04/04/of-science-crispr-cas9-and-asilomar/ (visited on 14th July 2018).

Gregorowius, D., Biller-Andorno, N. and Deplazes-Zemp, A. (2017). 'The role of scientific self-regulation for the control of genome editing in the human germline: the lessons from the Asilomar and the Napa meetings show how self-regulation and public deliberation can lead to regulation of new biotechnologies'. EMBO reports 18 (3), pp. 355-358. https://doi.org/10.15252/embr. 201643054.

Herndl, C. G. and Zarlengo, T. (2018). 'Matters of dwelling: releasing the genetically engineered Aedes Aegypti mosquito in Key West'. Social Epistemology 32 (1), pp. 41-62. https://doi.org/10.1080/02691728.2017.1397799.

Hilgartner, S. (2017). 'Governing gene editing: a constitutional conversation'. In: Gene editing, law and the environment: life beyond the human. Ed. by I. Braverman. 1st ed. New York, NY, U.S.A.: Routledge, pp. 186-193. https://doi.org/10.4324/9781315168418-11.

Hsu, P., Lander, E. and Zhang, F. (2014). 'Development and applications of CRISPR-Cas9 for genome engineering'. Cell 157 (6), pp. 1262-1278. https://doi.org/10.1016/j.cell.2014.05.010.

Hurlbut, J. B. (2015a). 'Limits of responsibility: genome editing, Asilomar and the politics of deliberation'. Hastings Center Report 45 (5), pp. 11-14. https://doi.org/10.1002/hast.484.

- (2015b). 'Remembering the future: science, law and the legacy of Asilomar university press scholarship'. In: Dreamscapes of modernity: sociotechnical imaginaries and the fabrication of power. Chicago, IL, U.S.A.: University of Chicago Press, pp. 126-151. https://doi.org/10.7208/chicago/9780226276663.003.0006.

Jasanoff, S., Hurlbut, J. B. and Saha, K. (2015). 'CRISPR democracy: gene editing and the need for inclusive deliberation'. National Academies of Science. Issues in Science and Technology 32 (1). URL: http: //issues .org/32-1/crispr-democracy -gene-editing-and-the-need-for-inclusive-deliberation/.

Jasanoff, S. (2005). 'In the democracies of DNA: ontological uncertainty and political order in three states'. New Genetics and Society 24 (2), pp. 139-156. https://doi.org/10.1080/14636770500190864.

Le Page, M. (16th June 2016). “Daisy-chain' gene drive vanishes after only a few generations'. NewScientist. URL: https://www. newscientist. com/article/209 3963-daisy-chain-gene-drive-vanishes-after-only-a-few-generations/ (visited on 6th May 2018).

Meghani, Z. and Kuzma, J. (2018). 'Regulating animals with gene drive systems: lessons from the regulatory assessment of a genetically engineered mosquito'. Journal of Responsible Innovation 5 (Sup1), S203-S222. https://doi.org/10.1080/23299460.2017.1407912.

NASEM (2016). Gene Drives on the Horizon: Advancing Science, Navigating Uncertainty, and Aligning Research with Public Values. Washington, DC, U.S.A.: National Academies Press. https ://doi .org/10.17226/23405. 
NASEM (2018). The promise of genome editing tools to advance environmental health research: proceedings of a workshop - in brief. Washington, DC, U.S.A.: National Academies Press. https://doi.org/10.17226/25136.

Neuhaus, C. P. (2018). 'Community engagement and field trials of genetically modified insects and animals'. Hastings Center Report 48 (1), pp. 25-36. https://doi.org/10.1002/hast.808.

Oxitec Ltd. (28th November 2018). Oxitec transitioning friendly ${ }^{\mathrm{TM}}$ self-limiting mosquitoes to 2nd generation technology platform, paving way to new scalability, performance and cost breakthroughs.

URL: https://www.oxitec.com/2nd-generation-platform/ (visited on 28th November 2018).

Parthasarathy, S. (2015). 'Governance lessons for CRISPR/Cas9 from the missed opportunities of Asilomar'. Ethics in Biology, Engineering and Medicine: An International Journal 6 (3-4), pp. 305-312. https://doi.org/10.1615/ethicsbiologyengmed.2016016470.

Phillips, S. (2017). 'Teaching public, scientific controversy: genetically modified mosquitoes in the technical writing classroom'. Journal of Technical Writing and Communication 49 (1), pp. 51-69. https://doi .org/10.1177/0047281617744507.

Sinkins, S. P. and Gould, F. (2006). 'Gene drive systems for insect disease vectors'. Nature Reviews Genetics 7 (6), pp. 427-435. https: //doi .org/10 .1038/nrg1870.

Target Malaria (2016). Target Malaria's response to the NAS recommendations in "Gene drives on the horizon: advancing science, navigating uncertaintly and aligning research with public values". URL: https://targetmalaria.org/wp-content/uploads/pd f/target-malaria-response-to-NAS-recommendations .pdf.

Tester, M. and Langridge, P. (2010). 'Breeding technologies to increase crop production in a changing world'. Science 327 (5967), pp. 818-822. https://doi.org/10.1126/science.1183700.

The Florida Keys Environmental Coalition (2018). Oxitec withdraws EPA application due to transition to 2nd generation Aedes Aegypti mosquito. [Facebook]. URL: https://www . facebook. com/groups/FKEC .org/.

Thomas, J. (9th June 2016). 'The National Academies' gene drive study has ignored important and obvious issues'. The Guardian. URL: https ://www . theguardian.c om/science/political-science/2016/jun/09/the-national-academies-gen e-drive-study-has-ignored-important-and-obvious-issues.

U.S. Food and Drug Administration (2016). Preliminary Finding of No Significant Impact (FONSI) in support of an investigational field trial of OX513A Aedes Aegypti mosquitoes. Silver Spring, MD, U.S.A. URL: http://www.fda.gov/downloads/An imalVeterinary/DevelopmentApprovalProcess/GeneticEngineering/Genetic allyEngineeredAnimals/UCM487379.pdf.

- (2017). Modernizing the regulatory system for biotechnology products: final version of the 2017 update to the coordinated framework for the regulation of biotechnology.

Silver Spring, MD, U.S.A. URL: https://www . fda.gov/downloads/Food/Ingred ientsPackagingLabeling/GEPlants/UCM537311. pdf.

White House (2015). Modernizing the regulatory system for biotechnology products: final version of the 2017 update to the coordinated framework for the regulation of biotechnology. Washington, DC, U.S.A.

URL: https://obamawhitehouse.archives.gov/sites/default/files/micros ites/ostp/2017_coordinated_framework_update.pdf.

Wynne, B. (2001). 'Creating public alienation: expert cultures of risks and ethics on GMOs'. Science as Culture 10 (4), pp. 445-481. https://doi.org/10.1080/09505430120093586. 
Cynthia Taylor (corresponding author) is a PhD candidate in the Department of Biological and Environmental Sciences at the University of Rhode Island and a member of the Science Education and Society (SEAS) research program. E-mail: cynthia_taylor@uri.edu.

Bryan Dewsbury is an Assistant Professor of Biology at the University of Rhode Island. He is the Principal Investigator for the Science Education and Society research program (http:/ /www.seasprogram.net/). E-mail: dewsbury@uri.edu.

Taylor, C. and Dewsbury, B. (2019). 'Barriers to inclusive deliberation and democratic governance of genetic technologies at the science-policy interface'. JCOM 18 (03), Y02. https:/ / doi.org/10.22323/2.18030402. 